\title{
Assessment of tax subjects' interaction under uncertainty of socio-economic processes
}

\author{
Hanna Kucherova ${ }^{1, *}$, Liudmyla Serhieieva ${ }^{2}$, and Olha Bilska $^{3}$ \\ ${ }^{1}$ Classic Private University, Economics Department, Zaporizhzhia, Ukraine \\ ${ }^{2}$ Zaporozhye State Medical University, Medical Physics, Biophysics and Further Mathematics Department, Ukraine \\ ${ }^{3}$ Classic Private University, Theoretical Economics, Marketing and National Economics Department, Zaporizhzhia, Ukraine
}

\begin{abstract}
Topicality of research into interactions between tax environment subjects is justified by growing uncertainty of changes in socio-economic processes. The aim of this study is to assess interaction between taxpayers, controlling bodies and public authorities in view of dominant paradigms and results of expert and sociological research on subjects with regard to the degree of their influence on tax environment climate. Interaction is defined as a certain type of relations between subjects that result in developing mutual influence which induces corresponding changes of their states. Interaction is essentially a poorly structured category, which dictates a need to use soft modeling and subjective evaluation methods (matrix models). According to the degree of influence on tax environment climate, public authorities are proved to be the most influential subject, while taxpayers are found to be the least influential. Summative value of subjects' interaction is set as Very Good. It is determined by taxpayers' data as the best among other subjects. Based on the analysis of dynamics in parameters and activity of interaction subjects it is argued that in order to improve subjects' interaction productivity, it is appropriate to improve the mechanisms of subjects' interaction with public authorities of all others.
\end{abstract}

\section{Introduction}

Research into interaction between different subjects of socio-economic system in regard to taxation is getting increasingly popular as current social and economic processes are highly dynamic and taxation mechanisms need to be adjusted to ensure timely and adequate response to changes. Ongoing crisis in Ukraine redoubles uncertainty in decision-making, therefore a vast majority of actors in the state socio-economic system compensate for the lack of information with subjective perception of objective circumstances of taxation.

The period of reforms has added weight to the roles of those subjects of the socio-economic system that make tax decisions, including authorities, taxpayers, controlling bodies and communities whose tax relations are regulated by regulatory and legal provisions. Present gaps and shortcomings of these provisions in Ukraine have shifted the focus of the scope of research towards subjectivism, which is seen as a derivative of an individual subject's knowledge and experience. Therefore, validity of decision-making requires additional substantiation through expert judgment.

It should also be noted that so far Ukraine has carried out reforms of both taxation system structure and taxation mechanisms which determined the trends of redefining the aims and ways of interaction between taxation subjects. In order to adequately respond to structural and dynamic changes in the socio-economic system, we should regularly assess its subjects' interaction in respective tax environment and identify high-potential options of main trends development, which is actually the aim of this study. Objective assessment will allow us to substantiate or specify the areas which require further improvement of subjects' interaction in order to ensure long-term equitable relations and good balance of all actors' interests. The dynamics of these subjects' interaction values will determine the productivity of their relations.

Interaction is a means of studying subjects and their environment, certain activity and type of behavior, a mechanism of their organization under certain conditions - all in one. Types of relations between subjects in tax environment are determined by their socio-economic roles (a taxpayer or a representative of controlling bodies [12], structural and functional relations established by the system to enable actualization of both system properties and interaction subjects properties within the system. In the context of this research relation is determined by the way subjects' interaction in tax environment is organized, their state being mutually conditioned by each other and itself. Relations represent a broader concept than interaction and have a different nature. They can only emerge between subjects in tax environment on condition that states of subjects or the system are fixed, acceptably equilibrium and stable enough. In this context, legal and regulatory framework acts as a stabilizing factor, knowledge of laws and regulations has a positive effect on conscientious payment of taxes $[13 ; 16 ; 17 ; 18]$. Awareness, understanding, quality and simplicity of tax processes [1;

\footnotetext{
*Corresponding author: kucherovahanna@gmail.com
} 
$2 ; 5 ; 14]$, a positive attitude to taxation, and financial resilience $[7 ; 8]$ predominantly (but not a hundred percent) ensure the required level of trustworthiness and timeliness of tax liabilities. In general, established relations between subjects in tax environment are realized within the framework of their interaction, which determines its effectiveness and productivity. In order to ensure objective assessment, functional and structural relations must be actualized, i. e. it is necessary to identify the set and structure of relations actual at period $t$.

Assessment of subjects' interaction in tax environment is generally based on analytical approaches and sociological research, a vast majority of which present their results in the form of a qualitative characterization of a selected set of parameters in certain areas of subjects' interaction. The above is explained by poor structuring of subjects interaction in tax environment due to informal factors of influence. For example, a global monitoring of interaction between taxpayers and controlling bodies is being done by stakeholders in the context of Forum on Tax Administration (FTA) [21] based on the International Survey on Revenue Administration (ISORA). The data it presents give full and clear idea of the tax administration system in terms of services, favorable conditions, technological development, easing administrative pressure for all groups of taxpayers and controlling bodies.

McKinsey assess interaction between taxpayers and controlling bodies using their own practices. Results of their research [4] suggest that across the globe, tax authorities diverge in the maturity of their relations with taxpayers in the following main areas: scale of digitized interactions, scale of advanced analytics, process automation, and talent management. Leading scientists explain differences in subjects' interaction in tax environment from the standpoint of development determinants of specific tax systems and scientific paradigm evolution.

At the level of individual research groups, leading scientists empirically substantiate the need to expand the standard neoclassical paradigm of rational egoism by taking into account multivarious behavioral strategies as a result of profound differentiation of taxpayers [2]. As a result of adopting a broader range of motivational factors of behavior, the paradigm of enforcement was updated and complemented with conceptual provisions of service trust models of interaction $[1 ; 16 ; 17]$ and relation ethics [3]. In particular, this study [9] suggested ways of organizing interaction between public authorities and taxpaying individuals by means of transforming cooperation forms from antagonistic to service trust ones. The determinants of building synergetic subject interaction in tax environment are considered to be power of the government and trust in it [5]. However, productivity and effectiveness of interaction between controlling bodies and taxpayers also depends on their good will to cooperate which is a compromise between a decision as to compliance with tax legislation and personal attitudes, opinions and assessments in terms of taxation. [16; 17]. Another research [15] studies reflexive interaction with taxpayers, controlling bodies and public authorities and arrives at the conclusion that they are satisfactory due to shortcomings of taxation regulatory framework and controlling bodies operation.

Thus, subjects' interaction in tax environment is a poorly structured category and quantitative evaluation of its parameters is always characterized with fuzzy reliability and unified approaches. The aim of this research is to assess subjects' interaction in tax environment based on theories of dominant paradigms and multiple-criteria results of sociological and expert assessments of taxpayers, controlling bodies and public authorities with regard to the degree of their influence on tax environment climate.

\section{Methods}

Interaction is a certain type of relations between subjects that result in developing mutual influence which induces corresponding changes of their states. Subjects' mutual influence is formed in the course of two reciprocal processes. One arises as a result of subject's own activity and potency, the other is a result of response to this activity. Combined, they form the dynamics of interrelation as a result of manifestation of dynamic change properties.

Forward call (process) from one subject to another is determined by the purpose of the interaction $\left(C_{p}\right)$ and resources involved to achieve it $\left(R_{c}^{p}, i j=<C_{p}, R_{c}^{p}, t>\right)$; backward call is determined by the subject's reaction to the call which is formed depending on the congruence of interaction purposes $\left(C_{p} \equiv C_{o}\right)$, availability and sufficiency of resources $\left(R_{c}{ }^{o}\right)$ presented in the format of possibilities and will to meet the purposes set: $j i=<C_{p \equiv o}, R_{c}^{o}, t>$, Fig. 1. There is also interaction of a subject with itself which is determined by selforganization processes ( $i i$ and $j j$ ).

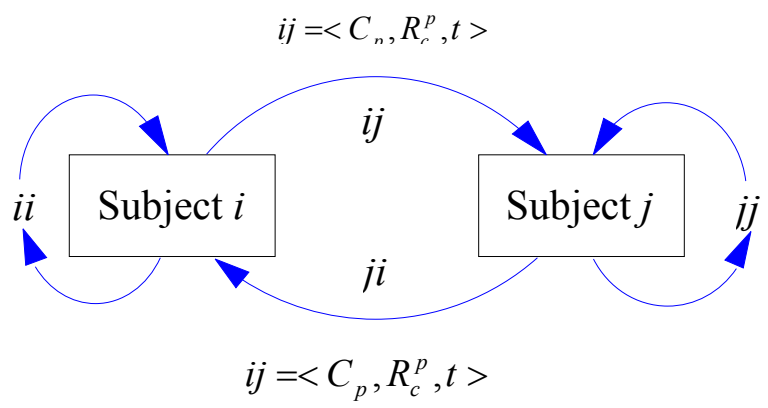

Fig. 1. The structure of interaction between $i$ and $j$.

Thus, these forward and backward processes characterize the effectiveness of interaction between the subjects in a particular situation, which is determined by the change of subjects' state $m$ as a result of their mutual influence $\Delta S_{t}^{m}$.

Direct evaluation of the subjects' states in tax environment is made by expertise, based on objective and subjective tax consequences for all interaction parties.

In the study [15], subject interaction structure is 
formalized through a system of weight adjacency matrices $A_{i j}=\left.\left.|| v\right|_{i j}\right|_{2 \times 2}$ where $v\left(I_{i}, I_{j}\right)$ is the forward relation weight and $v\left(I_{j}, I_{i}\right)$ is the backward relation weight. Adjacency matrix elements are determined by expertise in the absence of relevant statistical information and represent a set of subject interaction effectiveness values.

$$
A_{i j}=\left.|v|_{i j}\right|_{2 \times 2}=\left(\begin{array}{cc}
0 & v\left(I_{i}, I_{j}\right) \\
v\left(I_{j}, I_{i}\right) & 0
\end{array}\right) .
$$

However, this approach does not take into account the difference in weights of interaction subjects which also depends on their socio-economic roles. For example, in tax environment authorities and controlling bodies are closer to each other than to taxpayers due to the fact that controlling bodies act as an executive authority while taxpayers are interaction subjects with their own purposes regarding income distribution, which are opposite to the authorities' ones, and also a source of forming state resources and social demand for public services. That is, the role of taxpayers in tax environment is multifaceted.

Thus, interaction subjects' roles determine how much they influence the process of tax environment formation. It is logical that the state and controlling bodies have more leverage in the process of managerial decisionmaking in tax environment while taxpayers can only respond and adjust their economic mechanisms to new tax realities. Taking into account the difference in subjects' influence on the process of tax environment formation $\left(\mathrm{d}_{\mathrm{i}}\right)$, it seems appropriate to define the weight adjacency matrix of subjects' interaction more precisely:

$$
A_{i j}=\|\left.\left. v^{d_{i j}}\right|_{i j}\right|_{2 \times 2}=\left(\begin{array}{cc}
0 & v^{d i}\left(I_{i}, I_{j}\right) \\
v^{d j}\left(I_{j}, I_{i}\right) & 0
\end{array}\right) .
$$

Matrix eigenvalue $\lambda$ characterizes the value of $\mathrm{m}$ subjects' interaction and is determined in the following way:

$$
\lambda\left(I_{m}\right)=\sqrt{v^{d_{i}}\left(I_{i}, I_{j}\right) \times v^{d_{j}}\left(I_{j}, I_{i}\right)}, \lambda \in[0 ; 1]
$$

In order to estimate the influence on the process of tax environment formation $\left(d_{i}\right)$, we designed a pairwise comparison matrix underlying analytic hierarchy process [20]: $\quad A=\left\|a_{i j}\right\|_{m \times m}$ and relative priority vector $\left(\bar{d}_{1, \ldots .}, \bar{d}_{m}\right)^{T}$ using the geometric mean formula where relative weight values for every row of matrix $A$ are calculated as follows: $d_{i}=\frac{\sqrt[m]{a_{1 i, \ldots,} a_{i m}}}{\sum_{i=1}^{m} \sqrt[m]{a_{1 i, \ldots,} a_{i m}}}, i=\overline{1, m}$, where $m$ is the number of subjects which interact in tax environment.

Calculated adjacency matrix eigenvalues determine the proportion of subjects' influence on each other in tax environment while their batch forms a generalized adjacency matrix $A^{*}$. Generalized value of subjects' interaction can be determined as the root of the averaged sum of squares of the generalized adjacency matrix elements:

$$
O_{I}=\sqrt{\frac{\sum_{i=1}^{n} a_{i}^{2}}{n}}, O_{I} \in[0 ; 1]
$$

Further development of subjects' interaction in tax environment under invariable factors of influence can be forecast using an autonomous impulse process [19] when the state of interaction at a certain moment is calculated as follows:

$$
p(t)=p(o) \times\left[A^{t}\right], X(t)=X(0)+\left[A^{0}+A+A^{2}+\ldots+A^{t}\right],
$$

where $p(t)$ is the vector of changing values of subjects' interaction in the corresponding period of simulation, $p(0)$ is the vector of initial impulses, $A$ is the adjacency matrix, $t$ is simulation periods $(t$ is $0,1,2,3, \ldots, k)$ which represent the sequence of changes in the interaction state, $X_{(t)}$ is the value of subjects' interaction in the $t$ simulation period, $X_{(0)}$ is the value of subjects' interaction in the initial simulation period, $A$ is a unit matrix As a result, we can build a set of forecasting scenarios of subjects' interaction development, $S=\left\{S_{i}\right\}$.

\section{Materials}

Key roles of subjects that determine the general climate in tax environment need clarifying. Despite generally accepted grouping of taxpayers into large, medium and small ones according to the size of their business, in Ukraine it is large and small economic entities that set trends for taxation due to their fiscal significance and vulnerability, respectively. The above can be explained by the fact that medium taxpayers' characteristics partially overlap with those of both small and large taxpayers, therefore, in the context of statistical significance, when grouped according to certain issues, they are most often grouped with small payers and occasionally with large ones. In addition, in the course of active reforms of Ukrainian taxation system, tax consciousness has significantly improved in terms of acquired knowledge [14]. At the same time, updated tax mechanisms are not free from legislative shortcomings and gaps, which informed taxpayers use to their advantage. Hence, if previously we used to single out the state and controlling bodies, currently the judicial branch is gaining momentum while usual importance is being given to legislative branch and controlling bodies which act as executive branch. The above can be explained by the fact that a large number of decisions made by controlling bodies are appealed in court. For example, according to the State Fiscal Service of Ukraine, in 2018 [11] 18.8 thousand law suits on taxation were heard in court (generally on the following: "...seeking revocation of tax decision-notice..., appeal of customs decisions") totaling 61.3 billion UAH [11]. The proportion of judgments in favor of controlling bodies is $62.5 \%$ which is $63.1 \%$ of the total value [11]. The rest of these cases, 
$37.5 \%$ with the share of $36.9 \%$ of the total sum, were ruled in favor of taxpayers [11]. Also, in 2018 there were 4.6 thousand cases appealing customs decisions totaling 3.2 billion UAH and $10.8 \%$ of the judgments are in favor of controlling bodies which amounts $5.87 \%$ of the total sum [11]. The structure presented confirms the fact that actions of controlling bodies are partially frivolous which results in a large proportion of their decisions being appealed. It accounts for the negative attitude of taxpayers to controlling bodies, lack of trust in the government and taxation in general, which drives their tax behavior to be more opportunistic.

In the context of this study we determine the elements of subjects' interaction adjacency matrix using the data of the TADAT Performance Assessment Report of the State Fiscal Service (SFS) [22] and data of the Annual Business Climate Assessment (ABCA) [6] regarding taxation, to which we apply the standard values of Harrington's desirability scale [10], namely very good: $1.00-0.80$; good: $0.80-0.63$; satisfactory: 0.63-0.37; bad: $0.37-0.20$; very bad: $0.20-0$. Then we conform the TADAT SFS Performance Assessment scale, where criteria were assessed according to the [A,B,C,D] scale from the best (A) to the worst (D) value, with Harrington's desirability scale in the following way: $\mathrm{A}-1 ; \mathrm{B}-0.8 ; \mathrm{C}-0.63 ; \mathrm{D}-0.37$. The resulting integrated criteria values according to Harrington's desirability scale are presented in Table 1 . Thus, in terms of tax administration the level of interaction between controlling bodies and taxpayers is 0.72 This value underlies the corresponding adjacency matrix of subjects' interaction. In order to assess the interaction between the authorities and controlling bodies from taxpayers' perspective, we analyzed the results of Annual Business Climate Assessment (ABCA) [6] regarding taxation and found the following:

- Taxpayers find the level of trust in government low, $50 \%$ of respondents see the government as an impediment to do business, $25 \%$ of respondents consider main government institutions to be essential obstacles for business development.

- About $50 \%$ of respondents among small business representatives believe that informal relations with authorities are key to their business success. Direct support by the government is believed to be ineffective for business development, priority is given to creating proper business climate.

$-35 \%$ of individual respondents and $38 \%$ of legal entities think that their business growth is impaired by high rates of taxes and fees, $22 \%$ of individuals and $29 \%$ of legal entities blame it on burdensome tax administration and accounting, 18\% of individuals and $29 \%$ of legal entities refer to instability and frequent changes of economic legislation, $18 \%$ of individual respondents and $25 \%$ of legal entities mention regulatory pressure and other non-tax factors. Accordingly, with business growth and increasing size of enterprise tax conditions get significantly worse.

Thus, government influence on taxpayers is characterized as negative, hindering business development, which corresponds to approximately 0.20 on Harrington's desirability scale. As far as controlling bodies are concerned, their value is only important for taxpayers in the context of informal relations and is estimated to be 0.37 on the scale. Taking into account that taxpayers have more trust in business environment (other economic entities), improving business climate and, according to the SFS report (see Table 1), they timely file their tax declarations, pay taxes and fees, provide accurate and valid reports, we can calculate the value of their self-organization processes as a geometric mean of corresponding criteria, which equals 0.71 . Then, bearing in mind market realities as to possible purpose inconsistency or lack of resources that interaction subjects may have, backward relation constitutes 0.63 on Harrington's scale.

Table 1. Integrated values of criteria of subjects' interaction in Ukrainian tax environment*

\begin{tabular}{|c|c|c|c|}
\hline Criteria & $\begin{array}{l}\text { Actual } \\
\text { TADAT } \\
\text { value }\end{array}$ & $\begin{array}{c}\text { Harrington's scale } \\
\text { value }\end{array}$ & $\begin{array}{c}\text { Geometric } \\
\text { mean }\end{array}$ \\
\hline $\begin{array}{l}\text { Integrity of the } \\
\text { Registered } \\
\text { Taxpayer Base }\end{array}$ & $\mathrm{C} ; \mathrm{C}$ & $0.63 ; 0.63$ & 0.63 \\
\hline $\begin{array}{ll}\text { Effective Risk } \\
\text { Management }\end{array}$ & $\mathrm{C} ; \mathrm{D} ; \mathrm{C} ; \mathrm{C}$ & $\begin{array}{c}0.63 ; 0.37 ; 0.63 ; \\
0.63\end{array}$ & 0.55 \\
\hline $\begin{array}{l}\text { Supporting } \\
\text { Voluntary } \\
\text { Compliance }\end{array}$ & B; B; B & $0.8 ; 0.8 ; 0.8$ & 0.8 \\
\hline $\begin{array}{l}\text { Accountability } \\
\text { and Transparency }\end{array}$ & $\mathrm{B} ; \mathrm{B} ; \mathrm{C} ; \mathrm{A}$ & $0.8 ; 0.8 ; 0.63 ; 1$ & 0.8 \\
\hline \multicolumn{3}{|c|}{ Geometric mean for controlling bodies } & 0.67 \\
\hline $\begin{array}{ll}\text { Effective } & \text { Tax } \\
\text { Dispute } & \\
\text { Resolution } & \\
\end{array}$ & $\mathrm{A} ; \mathrm{B} ; \mathrm{A}$ & $1 ; 0.8 ; 1$ & 0.93 \\
\hline $\begin{array}{l}\text { Efficient Revenue } \\
\text { Management }\end{array}$ & $\mathrm{B} ; \mathrm{C} ; \mathrm{C}$ & $0.8 ; 0.63 ; 0.63$ & 0.68 \\
\hline \multicolumn{3}{|c|}{ Geometric mean for authorities } & 0.79 \\
\hline $\begin{array}{l}\text { Timely Filing of } \\
\text { Tax Declarations }\end{array}$ & $\mathrm{B}+; \mathrm{C}$ & $0.9 ; 0.63$ & 0.75 \\
\hline $\begin{array}{l}\text { Timely Payment } \\
\text { of Taxes }\end{array}$ & $\mathrm{A} ; \mathrm{A} ; \mathrm{A} ; \mathrm{B}$ & $1 ; 1 ; 1 ; 0.8$ & 0.94 \\
\hline $\begin{array}{l}\text { Accurate } \\
\text { Reporting in } \\
\text { Declarations }\end{array}$ & D+; B; D & $0.47 ; 0.8 ; 0.37$ & 0.52 \\
\hline \multicolumn{3}{|c|}{ Geometric mean for taxpayers } & 0.71 \\
\hline \multicolumn{3}{|c|}{ Geometric mean for all subjects } & 0.72 \\
\hline
\end{tabular}

\section{Results}

As a result, we have the following adjacency matrix of interaction between taxpayers $P$, with other subjects (public authorities $\mathrm{D}$, controlling bodies $K$ ):

$$
\begin{aligned}
& A_{P K}=\|\left.\left. v\right|_{P K}\right|_{2 \times 2}=\left(\begin{array}{cc}
0 & 0,37 \\
0,67 & 0
\end{array}\right), \lambda_{P K}=0,50, \\
& A_{P D}=\|\left.\left. v\right|_{P D}\right|_{2 \times 2}=\left(\begin{array}{cc}
0 & 0,37 \\
0,20 & 0
\end{array}\right), \lambda_{P D}=0,27, \\
& A_{P P}=\|\left.\left. v\right|_{P P}\right|_{2 \times 2}=\left(\begin{array}{cc}
0 & 0,71 \\
0,63 & 0
\end{array}\right), \lambda_{P P}=0,67 .
\end{aligned}
$$


Different degree of interacting subjects' influence on tax environment should be considered. Subjects that interact in tax environment can be assessed according to their influence on tax environment using a pairwise comparison matrix, see Table 2 .

Table 2. Subjects' pairwise comparison matrix according to their influence on tax environment formation, $d_{i}$.

\begin{tabular}{|c|c|c|c|c|c|c|c|}
\hline \multirow[b]{2}{*}{$\begin{array}{l}\text { Line numbers and names o- } \\
\text { compared subjects }\end{array}$} & \multicolumn{5}{|c|}{$\begin{array}{l}\text { Line numbers of } \\
\text { compared subjects }\end{array}$} & \multirow{2}{*}{\begin{tabular}{|l} 
Prio \\
rity \\
vect \\
or, \\
$\frac{d_{i}}{i}$
\end{tabular}} & \multirow[b]{2}{*}{$\begin{array}{l}\text { Weigh } \\
\text { ts, } d_{i}\end{array}$} \\
\hline & 1 & 2 & 3 & 4 & & & \\
\hline 1. Legislative branch & 1 & 2 & 4 & 6 & 8 & 3.29 & 0.46 \\
\hline 2. Judicial branch & 0.50 & 1 & 3 & 4 & 6 & 2.05 & 0.29 \\
\hline 3. Controlling bodies & 0.25 & 0.33 & 1 & 2 & 5 & 0.96 & 0.13 \\
\hline 4. Large taxpayers & 0.17 & 0.25 & 0.50 & 1 & 5 & 0.64 & 0.09 \\
\hline $\begin{array}{l}\text { 5. Small and medium } \\
\text { taxpayers }\end{array}$ & 0.13 & 0.17 & 0.20 & 0.20 & 1 & 0.24 & 0.03 \\
\hline Total & & & & & & 7.18 & 1 \\
\hline
\end{tabular}

Thus, the value of interaction on the level of specific subjects should be adjusted by the degree of their influence on tax environment formation. Therefore, the elements of weight adjacency matrices are specified as follows:

$$
\begin{gathered}
A_{P K}=\left.\left|v^{d_{P K}}\right|_{P K}\right|_{2 \times 2}=\left(\begin{array}{cc}
0 & 0,37^{0,09+0,03} \\
0,67^{0,13} & 0
\end{array}\right), \lambda_{P K}^{d_{P K}}=0,92, \\
A_{P D}=\left.\left.|| v^{d_{P D}}\right|_{P D}\right|_{2 \times 2}=\left(\begin{array}{cc}
0 & 0,37^{0,09+0,03} \\
0,20^{0,46+0,29} & 0
\end{array}\right), \lambda_{P D}^{d_{P D}}=0,52, \\
A_{P P}=\left.\left.|| v^{d_{P P}}\right|_{P P}\right|_{2 \times 2}=\left(\begin{array}{cc}
0 & 0,71^{0,09+0,03} \\
0,63^{0,09+0,03} & 0
\end{array}\right), \lambda_{P P}^{d_{P P}}=0,95 .
\end{gathered}
$$

Specifying the degree of influence according to the weights in Table 2, we determine the values of interaction on the level of large $(V P)$ and small $(M P)$ taxpayers, judiciary $(S)$ and legislative institutions $(Z)$.

$$
\begin{gathered}
A_{V P}^{K}=\left.\left.|v|\right|_{V P} ^{K}\right|_{2 \times 2}=\left(\begin{array}{cc}
0 & 0,37^{0,09} \\
0,67^{0,13} & 0
\end{array}\right), \lambda_{V P}^{K}=0,93, \\
A_{P Z}=\left.\left.|| v\right|_{V P} ^{Z}\right|_{2 \times 2}=\left(\begin{array}{cc}
0 & 0,37^{0,093} \\
0,20^{0,46} & 0
\end{array}\right), \lambda_{V P}^{Z}=0,66, \\
A_{P S}=\left.\left.|| v\right|_{V P} ^{S}\right|_{2 \times 2}=\left(\begin{array}{cc}
0 & 0,37^{0,09} \\
0,20^{0,29} & 0
\end{array}\right), \lambda_{V P}^{S}=0,76, \\
A_{P P}=\left.\left.|| v\right|_{V P} ^{M P}\right|_{2 \times 2}=\left(\begin{array}{cc}
0 & 0,71^{0,09} \\
0,63^{0,09} & 0
\end{array}\right), \lambda_{V P}^{M P}=0,96 .
\end{gathered}
$$

Similar calculations for controlling bodies arrive at the following results:

$$
A_{P K}=\left.\left.|| v\right|_{P K}\right|_{2 \times 2}=\left(\begin{array}{cc}
0 & 0,67^{0,13} \\
0,71^{0,09+0,03} & 0
\end{array}\right), \lambda_{P K}=0,95,
$$

$$
\begin{gathered}
A_{K D}=\left.\left.|| v\right|_{K D}\right|_{2 \times 2}=\left(\begin{array}{cc}
0 & 0,67^{0,13} \\
0,79^{0,46+0,29} & 0
\end{array}\right), \lambda_{K D}=0,89, \\
A_{K K}=\left.\left.|| v\right|_{K K}\right|_{2 \times 2}=\left(\begin{array}{cc}
0 & 0,67^{0,13} \\
0,37^{0,13} & 0
\end{array}\right), \lambda_{K K}=0,91 .
\end{gathered}
$$

As we can see, controlling bodies have the same influence on other subjects, as according to the SFS Report they function as executive authorities in terms of taxation, so the value of forward relation is 0.67 for all subjects. According to the SFS assessment, public authorities' value is 0.79 . Self-organization processes in controlling bodies are determined as built in the way their functions duplicate, so it corresponds to 0.37 on Harrington's scale.

The results of subjects' interaction with public authorities are presented below:

$$
\begin{gathered}
A_{D P}=\left.\left.|| v\right|_{D P}\right|_{2 \times 2}=\left(\begin{array}{cc}
0 & 0,68^{0,46+0,29} \\
0,71^{0,09+0,03} & 0
\end{array}\right), \lambda_{P D}=0,85, \\
A_{D K}=\left.|v|_{D K}\right|_{2 \times 2}=\left(\begin{array}{cc}
0 & 0,93^{0,46+0,29} \\
0,37^{0,13} & 0
\end{array}\right), \lambda_{D K}=0,91, \\
A_{D D}=\left.|v|_{D D}\right|_{2 \times 2}=\left(\begin{array}{cc}
0 & 0,68^{0,46+0,29} \\
0,72^{0,46+0,29} & 0
\end{array}\right), \lambda_{D D}=0,81 .
\end{gathered}
$$

The state interacts with taxpayers through the mechanisms of income formation, whose value is 0.68 according to the SFS Report criteria. Public authorities interact with controlling bodies in terms of taxation through effective tax dispute resolution using regulatory means. Its value is 0.93 according to the SFS Report criteria. Forward self-organization processes for public authorities in terms of taxation is evaluated according to the SFS Report criteria and equals 0.79 , while backward processes are evaluated according to the criteria of all interaction subjects and equals 0.72 .

Based on the received eigenvalues of adjacency matrices, a generalized matrix of interaction between public authorities, controlling bodies and taxpayers in tax environment can be designed:

$$
A^{*}=\left(\begin{array}{lll}
0,95 & 0,50 & 0,27 \\
0,95 & 0,91 & 0,89 \\
0,85 & 0,91 & 0,81
\end{array}\right) .
$$

Summative value of subjects' interaction in tax environment is, formula (4):

$$
O_{I}=\sqrt{\frac{\sum_{i=1}^{m} a_{i}^{2}}{m}}=0,81 .
$$

Based on the formula (5), we can study the dynamics of subjects' interaction activity and parameters of this interaction. The results are shown in Figures 2, 3. 


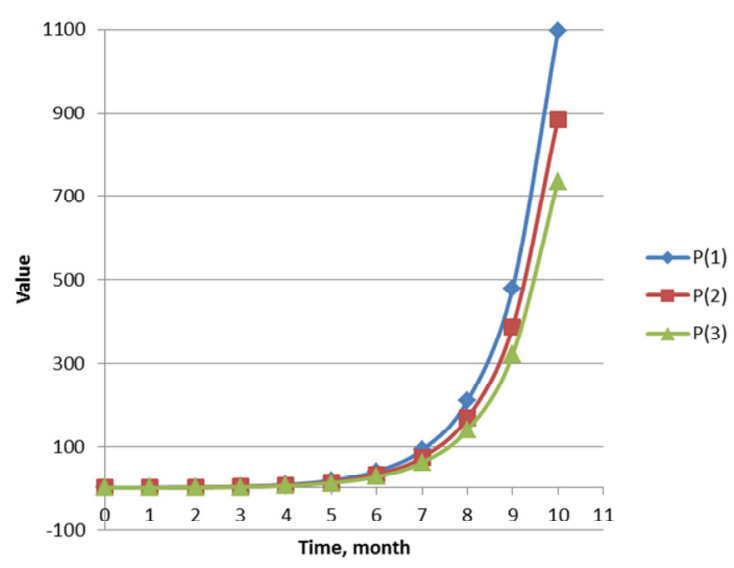

Fig. 2. Subjects' interaction activity dynamics.

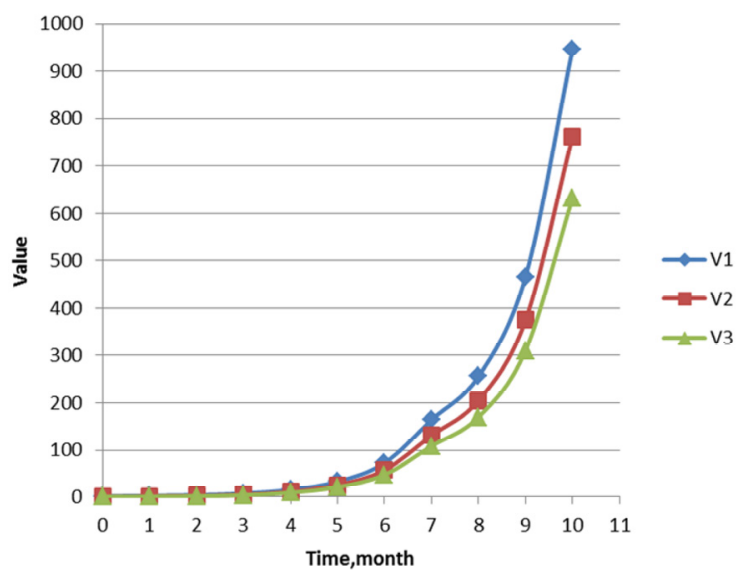

Fig. 3. Subjects' interaction parameters dynamics.

As can be seen from Figure 2, the intensity of interaction for public authorities and controlling bodies is almost identical up to step 3, after which the activity of public authorities gradually slows down. On the one hand, it is due to their close functional and structural relations in taxation process. On the other hand, in the course of time a system needs more time for the procedure of managerial decision-making, which, in the context of the subjects' interaction, is reflected by delayed response, in our case on the part of public authorities. At the same time, the trends in the interaction of controlling bodies and taxpayers get closer in steps $1-3$, and then controlling bodies' activity curve is more moderate, but it corresponds with taxpayers' one.

Based on the dynamics of parameters which describe subjects' interaction (Figure 3), we can see that the curves of public authorities and controlling bodies are close in steps 1-2. After that, public authorities' dynamics fall behind in tempo. Taxpayers' interaction parameters are more dynamic as compared to other subjects' interaction. Thus, it can be argued that in order to improve the interaction results for all subjects in taxation environment, it is appropriate to revise and adjust the mechanisms of subjects' interaction with public authorities, whose parameter dynamics grows dissonant with other subjects' interaction trends in the course of time.

\section{Conclusions}

This research deals with assessment of interaction between taxpayers, controlling bodies and public authorities in view of dominant paradigms and results of expert and sociological research on the subjects with regard to the degree of their influence on tax environment climate. Interaction is defined as a certain type of relations between subjects that result in developing mutual influence which induces corresponding changes of their states. Subjects' mutual influence is presented as two reciprocal processes: forward process arises as a result of subject's own activity and potency and is determined by interaction purpose and resources involved, backward process is a result of response to the activity, it is formed depending on the congruence of interaction purposes, availability and sufficiency of resources presented in the format of possibilities and will to meet the goals set. There is also interaction of a subject with itself which is determined by self-organization processes. Interaction is essentially a poorly structured category, which dictates a need to use soft modeling and subjective evaluation methods. The suggested approach is based on an adjacency matrix whose elements are eigenvalues of weight matrices of subjects' pairwise interaction. Matrix elements are determined by expertise. Based on the pairwise comparison matrix, subjects are differentiated according to the degree of their influence on tax environment climate. As a result, public authorities are found to be the most influential subject, while small and medium taxpayers are the least influential. Summative value of subjects' interaction is 0.81 which is determined by taxpayers' data as the best among other subjects. Dynamics of parameters and activity of interaction subjects have been studied by means of autonomous impulse process. It has been proved that in order to improve subjects' interaction productivity, it is appropriate to improve the mechanisms of subjects' interaction with public authorities of all others. The results of this research allow us to substantiate strategies aimed at improving and optimizing subjects' interaction in tax environment upon the criterion of maximizing effectiveness and productivity. In addition, significance of the issue justifies the need for a system of subjects' interaction monitoring for the sake of higher accuracy of tax result assessment. Future research will develop strategies to improve and monitor subjects' interaction in tax environment.

\section{References}

1. Abdul-Razak, A., Adafula, C.J.: Evaluating taxpayers' attitude and its influence on tax compliance decisions in Tamale, Ghana. Journal of Accounting and Taxation. 5(3), 48-57 (2013). doi:10.5897/JAT2013.0120

2. Alm, J. Kirchler, E., Muehlbacher, S., Gangl, K., Hofmann, E., Kogler, C., Pollai, M.: Rethinking the research paradigms for analysing tax compliance behaviour. In CESifo forum. München: ifo Institut- 
Leibniz-Institut für Wirtschaftsforschung an der Universität München. 13.2, 33-40 https://www.researchgate.net/publication/25445267 7 Rethinking the Research_Paradigms for_Analys ing_Tax_Compliance_Behaviour (2012). Accessed 21 January 2019

3. Alm, J., Torgler, B.: Do ethics matter? Tax compliance and morality. J Bus Ethics. 101, 1-17 (2012)

4. Barnay, A. Davis, J., Dimson, J., Gibbs, E., Korn, D.: Four innovations reshaping tax administration. McKinsey and company. https://www.mckinsey.com/industries/public-sector /our-insights/four-innovations-reshaping-taxadministration (2018). Accessed 21 January 2019

5. Batrancea, L.: Taxpayers And Tax Authorities Interacting Within The Mena Region: The Nexus Between Trust, Power And Compliance. Annals of Faculty of Economics, University of Oradea, Faculty of Economics. 1(2), 241-250. https://ideas.repec.org/a/ora/journl/v2y2014i2p241250.html (2014). Accessed 21 January 2019

6. Bespalko, V. Freik, N., Fedets, I., Kuziakiv, O.: Annual Business Climate Assessment, ABCA. USAID.

http://www.ier.com.ua/en/sme development/ABCA (2016). Accessed 8 January 2019

7. Devos, K.: Factors influencing individual taxpayer compliance behaviour. Springer Science \& Business Media. (2014). doi:10.1007/978-94-007-7476-6

8. Fadzilah, E.N., Mustafa, R.M., Putri, N.K.: The Effect of Tax Understanding, Tax Payness Consciousness, Quality of Tax Service, and Tax Sanctions on Compulsory Tax of SMEs In Banyumas. Acta Universitatis Danubius. Economica. 13(4), 28-38 (2017)

9. Gangl, K., Hofmann, E., Kirchler, E.: Tax authorities' interaction with taxpayers: A conception of compliance in social dilemmas by power and trust. New Ideas Psychol. 37, 13-23 (2015). doi:10.1016/j.newideapsych.2014.12.001

10. Harrington, E.C.: The Desirability Function. Industrial quality control. 21, 494-498 (1965)

11. Information about appeals decisions Official portal State Fiscal Service of Ukraine. http://sfs.gov.ua/diyalnist-/pokazniki-roboti/ vregulyuvannya-podatkovih/informatsiya-schodooskarjen-rishen/ (2018). Accessed 21 January 2019

12. Kim, J.S.: Analysis of the Tax Consciousness of a Taxpayer and a Tax Agent. The Journal of the Korea Contents Association. 8(10), 142-150 (2008). doi:10.5392/JKCA.2008.8.10.142

13. Kirchler, E., Niemirowski, A., Wearing, A.: Shared subjective views, intent to cooperate and tax compliance: Similarities between Australian taxpayers and tax officers. Journal of Economic

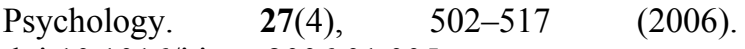
doi:10.1016/j.joep.2006.01.005
14. Kucherova, H.: Methods of Evaluating Taxpayers' Tax Consciousness. In: Nestorenko, O., Pokusa, O. (ed.) Transformations in Contemporary Society: Economic Aspects, pp. 243-250. Opole, The Academy of Management and Administration in Opole

http://pedagogika.wszia.opole.pl/ebook/Monografia 2017_3.pdf Accessed 19 January 2019

15. Kucherova, H.Y., Komazov, P.V.: Substantiation of tax consciousness model for subjects of taxation on the basis of reflexive interaction. Central European journal for science and research. 3(16), 9-19 (2015)

16. Muehlbacher, S., Kirchler, E., Schwarzenberger, H.: Voluntary versus Enforced Tax Compliance: Empirical Evidence for the "Slippery Slope" Framework. European Journal of Law and Economics. 32, 89-97 (2011)

17. Muehlbacher, S., Kogler C., Kirchler, E.: An Empirical Testing of the Slippery Slope Framework: The Role of Trust and Power in Explaining Tax Compliance, University of Vienna Working Paper. (2011). doi:10.1007/s10657-011-9236-9

18. Pertiwi, D.N.: The Influence of Tax Consciousness, Service Tax Authorities and Tax Sanctions on Tax Compliance (Survey On Individual Taxpayer Conducting Business Operations and Professional Service in Jakarta). Dissertation, State Islamic University Syarif Hidayatullah Jakarta (2013)

19. Roberts, F.S.: Discrete Mathematical Models, with Applications to Social, Biological and Environmental Problems. Prentice-Hall, Englewood Cliffs (1976)

20. Saaty, T.L.: The Analytic Hierarchy Process. McGraw-Hill, New York (1980)

21. Tax Administration: Comparative Information on OECD and Other Advanced and Emerging Economies. OECDiLibrary (2017). doi:10.1787/23077727

22. Wolf, N.B., Khwaja, M., Andreasson, A., Fink, F.: Performance Assessment Report Ukraine Tax Administration Diagnostic Assessment Tool (TADAT). The World Bank. http://sfs.gov.ua/data/material/000/259/339853/Ukra ine_TADAT_2018_Performance_Assessment Report_Final_EN_6455958_v1_DMSDR1S.pdf (2018). Accessed 21 January 2019 